\title{
Scanning electron microscopy studies of erythrocytes in spinocerebellar degeneration
}

\author{
YUZURU YASUDA, ICHIRO AKIGUCHI, HIDEO SHIO, MASAKUNI KAMEYAMA \\ From the Department of Neurology, Faculty of Medicine, Kyoto University, Kyoto, Japan
}

SUMMARY Spinocerebellar degeneration is a heredofamilial disease of unknown aetiology. The shape of erythrocytes as revealed by scanning electron microscopy was studied in this disease. Echinocytes I, as defined by Bessis, were seen more frequently in spinocerebellar degeneration than in age and sex matched controls $(7 \cdot 2 \pm 1.5 \%$ in spinocerebellar degeneration, $3.4 \pm 1 \cdot 2 \%$ in controls, $\mathrm{p}<0.001)$, Parkinson's disease, motor neuron disease, myopathy, and Huntington's chorea. Erythrocyte deformability was impaired to a greater extent in spinocerebellar degeneration than in the controls when the $\mathrm{pH}$ was raised from $7 \cdot 2$ to $8 \cdot 0$; Echinocytes I in spinocerebellar degeneration increased from $8.4 \pm 0.6$ to $15.4 \pm 2.4 \%$, in the control group from $2.8 \pm 1 \cdot 2$ to $13 \cdot 3 \pm 2 \cdot 1 \%$. In spinocerebellar degeneration no significant correlation was found between the level of serum low density lipoprotein and the number of Echinocytes I. In both groups there was a significant correlation between the occurrence of Echinocytes I and age, and the difference of Echinocytes I was greater in aged subjects in spinocerebellar degeneration. The data suggest that membrane abnormality in erythrocytes exists in spinocerebellar degeneration and may be accelerated with the advance of age.

Membrane abnormalities have recently been reported in heredo-familial disorders. ${ }^{12}$ Stomatocytosis $^{3}$ and abnormal electron spinresonance ${ }^{4}$ of erythrocytes in Huntington's chorea indicate that the physical state of membrane proteins is altered. An abnormal electron spinresonance of erythrocytes was also detected in myotonic dystrophy ${ }^{56}$ and Duchenne dystrophy. ${ }^{7}$ A marked depletion of intramembranous particles of erythrocytes in Duchenne dystrophy, ${ }^{8}$ which was detected by freeze-fracture studies, indicated that the internal molecular architecture was abnormal.

Spinocerebellar degeneration is a heredofamilial disorder of unknown aetiology, ${ }^{9-11}$ containing many subtypes which suggests that the aetiology may be quite complex. Spinocerebellar degeneration is characterised clinically by a disturbance of motor regulation such as ataxia, incoordination, dysmetria, asynergia, and intention tremor, and pathologically by atrophy and degeneration of the cerebellum, olive, pons, spinal cord, and other regions.

\footnotetext{
Address for reprint requests: Dr Yuzuru Yasuda, Department of Medicine, Faculty of Medicine, Kyoto University, 54 Kawaracho Shogoin Sakyo-ku, Kyoto 606, Japan.
}

Received 30 March 1982 and in revised form 16 March 1983. Accepted 16 April 1983
Recently the abnormality of serum high density lipoprotein in Friedreich's ataxia has been found in one study, ${ }^{12}$ but not in another. ${ }^{13}$ As there is a relationship between lipid and membrane, membrane abnormality may exist in Friedreich's ataxia. Since no investigation of erythrocyte shape in spinocerebellar degeneration has been reported, we attempted to study the erythrocyte morphology in that disease, using scanning electron microscopy. However the study of erythrocytes in neurological diseases by scanning electron microscopy is one of poor reproducibility from laboratory to laboratory. ${ }^{14-19}$ The procedures before fixation greatly affect the shape of erythrocytes. Therefore we fixed the erythrocytes immediately after drawing blood, not using centrifugation, and carried out critical point drying. To ascertain the reproducibility, we reexamined some controls and patients after an interval of more than one month.

\section{Methods}

Control subjects consisted of normal healthy individuals and patients with no neurological disorders or inherited diseases (male: 10 , female: 12 , mean age $57 \cdot 3$ years, range 29 to 73). Patients with spinocerebellar degeneration consisted of 13 males and nine females with a mean age of 
Table 1 The percentage of Echinocyte I in controls and neurological diseases*

\begin{tabular}{|c|c|c|c|}
\hline & Echinocyte I & $\begin{array}{l}\text { Number of } \\
\text { cases }\end{array}$ & $\begin{array}{l}\text { Mean age, } \\
y r\end{array}$ \\
\hline $\begin{array}{l}\text { Controls } \\
\text { SCD } \\
\text { Parkinson's disease } \\
\text { Motor neuron disease } \\
\text { Myopathy } \\
\text { Huntington's chorea } \\
\text { Others }\end{array}$ & $\begin{array}{l}3 \cdot 4 \pm 1 \cdot 2(\%) \\
7 \cdot 2 \pm 1 \cdot 5 \dagger \\
3 \cdot 9 \pm 2 \cdot 0 \\
4 \cdot 1 \pm 1 \cdot 0 \\
2 \cdot 7 \pm 0.3 \\
3 \cdot 7 \pm 0 \cdot 1 \\
4 \cdot 3 \pm 1 \cdot 4\end{array}$ & $\left.\left.\begin{array}{l}22 \\
22 \\
7 \\
5 \\
5 \\
2 \\
2 \\
2 \\
7\end{array}\right\} \begin{array}{rr}\text { M10 } & \text { F12) } \\
13 & 9 \\
3 & 2 \\
1 & 1 \\
1 & 1 \\
3 & 4\end{array}\right)$ & $\begin{array}{l}57 \cdot 3 \\
53 \cdot 7 \\
56 \cdot 1 \\
39 \cdot 4 \\
37 \cdot 0 \\
49 \cdot 0 \\
43 \cdot 5\end{array}$ \\
\hline
\end{tabular}

*Values are Mean \pm SD.

tDifferent from the other $(p<0.001)$.

53.7 years (range 28 to 78 ). Table 1 includes findings from other neurological patients. Patients with diabetes mellitus or liver diseases were excluded from the analysis, because of possible red cell abnormality. The classification of spinocerebellar degeneration was carried out according to the clinical course of the disease, neurological findings, and laboratory examinations including computed tomography. Fifteen patients with olivopontocerebellar atrophy, five with late cortical cerebellar atrophy, and two with MarieSanger-Brown type were included. Two out of 15 with olivopontocerebellar atrophy and three with late cortical

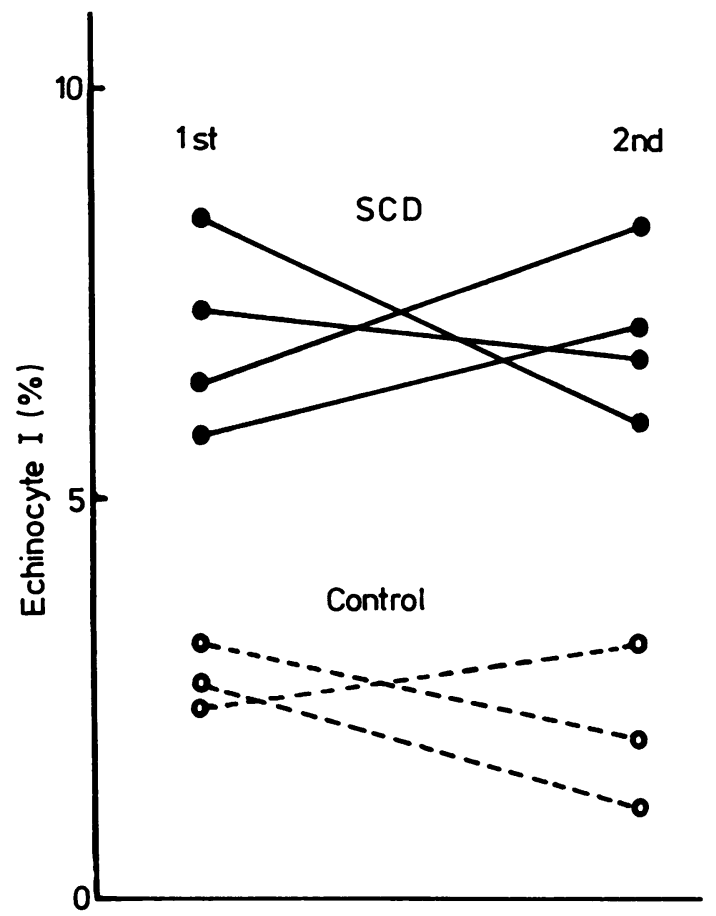

Fig 1 The erythrocytes of three controls and four patients with spinocerebellar degeneration were investigated using the same methods after a more than one month interval. The occurrence of the echinocytes in these cases were substantially unchanged. cerebellar atrophy were familial forms of the disease. None of the controls was taking drugs which could affect erythrocyte shape. Only two patients with olivopontocerebellar atrophy were taking such drugs: one salicylate, and another thiazide diuretics. Blood was collected before breakfast. No anticoagulant was used. Three drops of blood were dripped directly from the syringe into $2 \%$ glutaraldehyde solution in $0.05 \mathrm{M}$ phosphate buffer $(\mathrm{pH}$ $7 \cdot 2,340 \mathrm{~m} 0 \mathrm{sm})$. The test tube was inverted gently three times and the blood cells were fixed for 1 hour. The erythrocytes settled by gravity. One drop from the erythrocyte layer was then mounted on a piece of glass $(3 \times 3 \mathrm{~mm})$ in a moist Petri dish, and was then immersed for 10 minutes in $0 \cdot 1 \mathrm{M}$ sucrose solution ( $\mathrm{pH} 7 \cdot 2,0 \cdot 1 \mathrm{M}$ phosphate buffer, $320 \mathrm{~m} 0 \mathrm{sm}$ ). It was not necessary to cover the glass with collagen etc., as erythrocytes can adhere to the glass after about 5 minutes with the remnants of the serum protein. By moving a piece of glass gently by pincette from one small Petri dish filled with solution to another, cells were dehydrated through ethanol in ascending concentrations $(50,60,70,80,90$, and $100 \%)$, and immersed for 20 minutes in isoamylacetate solution. Critical point drying procedure was employed (Hitachi, HCP-1) and cells were coated with gold vapour (Eiko IB3 Ion Coater). The cells were photographed at a magnification of 1000 to 10000 with a Hitachi HFS-2S, and Mini SEM MSM 5. A mean of 665 erythrocytes per sample was analysed according to Bessis $^{20}$ and Hattori. ${ }^{21}$ Cells which bound together were excluded from analysis. The studies were done blind. To ascertain the reproducibility of the methods we examined the erythrocytes of three controls and four patients with spinocerebellar degeneration using the same procedures after a more than one month interval. The occurrence of the echinocytes in these cases were substantially reproducible (fig 1).

\section{Results}

There was no difference among controls, patients with spinocerebellar degeneration, Parkinson's disease, motor neuron disease, myopathy, and Huntington's chorea as far as the percentage of stomatocytes, elliptocytes, and knizocytes, except for stomatocytosis in Huntington's chorea. One patient with Huntington's chorea had stomatocytosis of $18.7 \%$. Only Echinocytes I were more frequently seen in spinocerebellar degeneration than in age and sex matched controls $(7.2 \pm 1.5 \%$ in spinocerebellar degeneration, $3.4 \pm 1.2 \%$ in controls, $p<0.001$ ), Parkinson's disease, motor neuron disease, myopathy, and Huntington's chorea (tables 1,2).

If the cell had even a little crenation, we classified it as Echinocyte I. Figure 2B shows a normal discocytic shape of erythrocyte.

In neither group were there any sex-related differences. The percentage of Echinocytes I was 7.3 \pm $1.8 \%$ in olivopontoce rebellar atrophy, $7.7 \pm 1.1 \%$ in late cortical cerebellar atrophy, and $6.0 \pm 0.8 \%$ in Marie-Sanger-Brown type. There were no 
Table 2 Erythrocyte shape in spinocerebellar degeneration and controls*

\begin{tabular}{lcc}
\hline & $\begin{array}{l}\text { Spinocerebellar } \\
\text { degeneration }\end{array}$ & Controls \\
\hline Discocyte & $84 \cdot 5 \pm 3 \cdot 8(\%)$ & $87 \cdot 1 \pm 3 \cdot 6(\%)$ \\
Echinocyte I & $7 \cdot 2 \pm 1 \cdot 5 \dagger$ & $3.4 \pm 1 \cdot 2 \dagger$ \\
Stomatocyte & $3 \cdot 9 \pm 2 \cdot 6$ & $4 \cdot 1 \pm 3 \cdot 0$ \\
Elliptocyte & $0.4 \pm 0 \cdot 4$ & $0.7 \pm 0.9$ \\
Knizocyte & $1 \cdot 7 \pm 1 \cdot 3$ & $1 \cdot 3 \pm 1 \cdot 0$ \\
\hline
\end{tabular}

${ }^{*}$ Values are Mean \pm SD.

tp $<0.001$.

significant differences among the types of spinocerebellar degeneration, but these values were significantly different from the controls $(p<0.001$ in olivopontocerebellar atrophy and late cortical cerebellar atrophy, $\mathrm{p}<0.02$ in Marie-SangerBrown type) (fig 3).

It is well known that the erythrocyte tends to be echinocytic in an alkaline medium. Therefore the effect of $\mathrm{pH}$ on erythrocyte shape was also examined. Specimens were taken from five persons from each group. When the $\mathrm{pH}$ was raised from $7: 2$ to $8 \cdot 0$, Echinocyte $I$ in spinocerebellar degeneration increased from $8.4 \pm 0.6$ to $15.4 \pm 2.4 \%$, in control group from $2 \cdot 8 \pm 1 \cdot 2$ to $13 \cdot 3 \pm 2 \cdot 1 \%(\mathrm{p}<0.02)($ fig 4).

A correlation between age and Echinocyte I was found in both groups, and the difference of Echinocyte I was greater in aged subjects with spinocerebellar degeneration (fig 5).

No correlation between the number of Echinocyte I and the concentration of serum low density lipoprotein or the ratio between high and low density lipoprotein was found in spinocerebellar degeneration (fig 6).

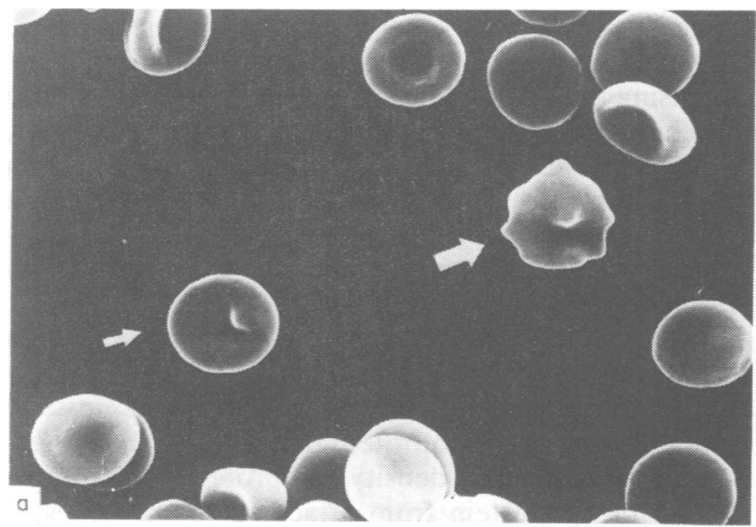

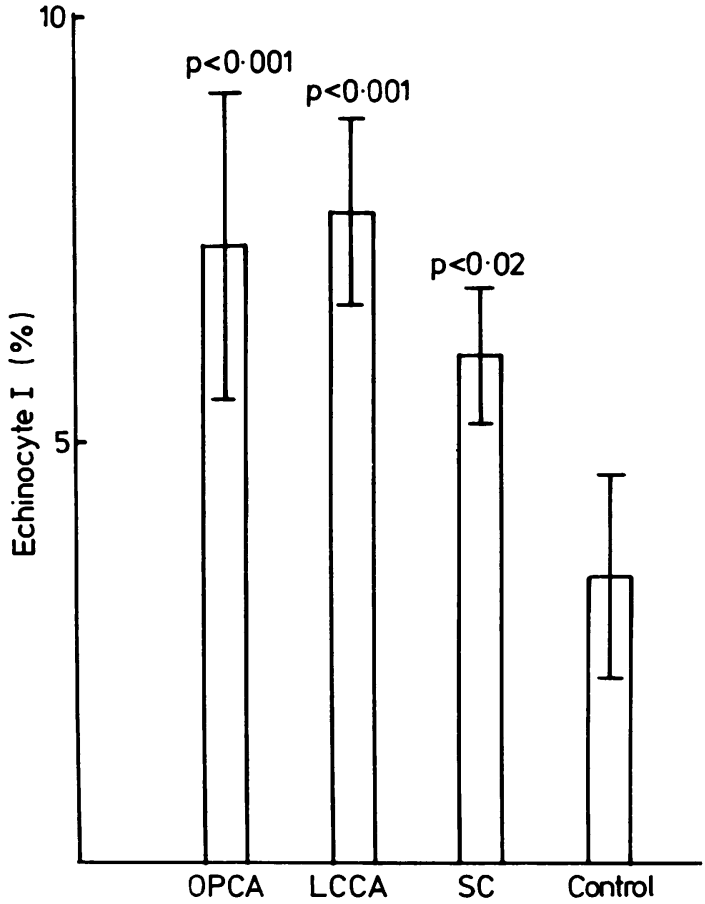

Fig 3 There is no significant difference in the occurrence of echinocytes among olivopontocerebellar atrophy, late cortical cerebellar atrophy, and the Marie-Sanger-Brown type (spinocerebellar form: SC).

Significant difference was found between patients and normal controls.

\section{Discussion}

Scanning electron microscopy studies of erythrocytes have been done in Huntington's chore $\mathrm{a}^{3}$ and

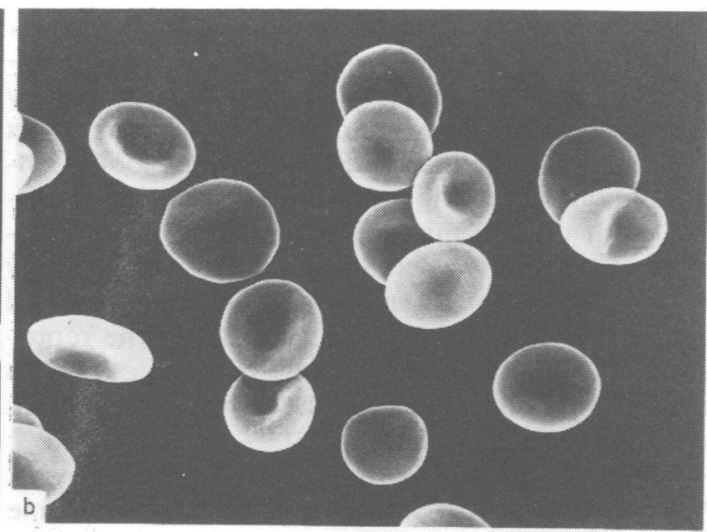

Fig 2 A: Spinocerebellar degeneration $(\times 3000)$, B: controls $(\times 3000)$ Echinocytes were more frequently seen in spinocerebellar degeneration than in controls. In A, small arrow indicates Echinocyte I, large arrow, Echinocyte II. A cell with even a little crenation was classified as Echinocyte I. 


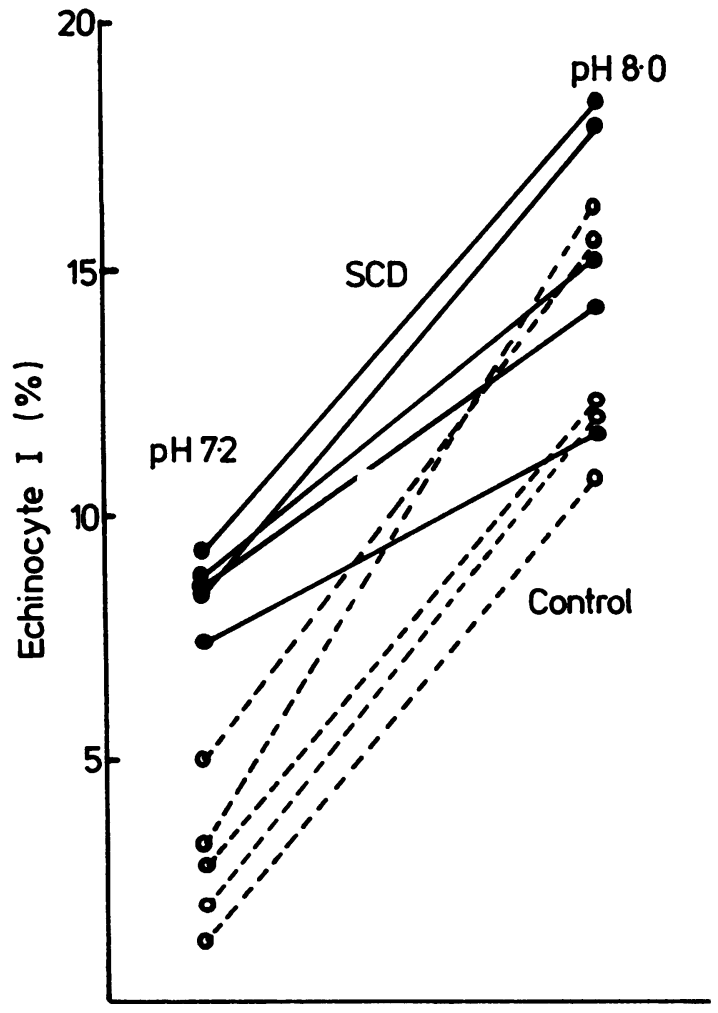

Fig 4 When the $\mathrm{pH}$ was raised from $7 \cdot 2$ to $8 \cdot 0$, Echinocyte $I$ in spinocerebellar degeneration increased from $8.4 \pm 0.6$ to $15.4 \pm 2.4 \%(p<0.02)$, in controls group from $2.8 \pm$ $1 \cdot 2$ to $13 \cdot 3 \pm 2 \cdot 1 \%($ Mean $\pm S D)$.

Duchenne dystrophy ${ }^{14-19}$ but not in spinocerebellar degeneration. The study of erythrocytes in neurological diseases by scanning electron microscopy is one of poor reproducibility from laboratory to laboratory, for example in Duchenne dystrophy. ${ }^{14-19}$ As the procedures before fixation greatly affect the shape of erythrocytes, it is better to fix erythrocytes immediately after drawing blood. Centrifugation and drying procedures (air drying or critical point drying) may affect the shape of erythrocytes. Therefore we fixed erythrocytes immediately after drawing, not using centrifugation, and carried out critical point drying. We ascertained the reproducibility of the method by examining some controls and patients using the same procedure after a more than one month interval.

Normal erythrocytes display biconcave discocytes. Also, various factors can cause discocytes to become echinocytes: that is, presence of an alkaline condition, $\mathrm{Ca},{ }^{22}$ fatty acid, salicylate, and so on. ${ }^{23-28}$

In this study Echinocytes $I$ were increased in

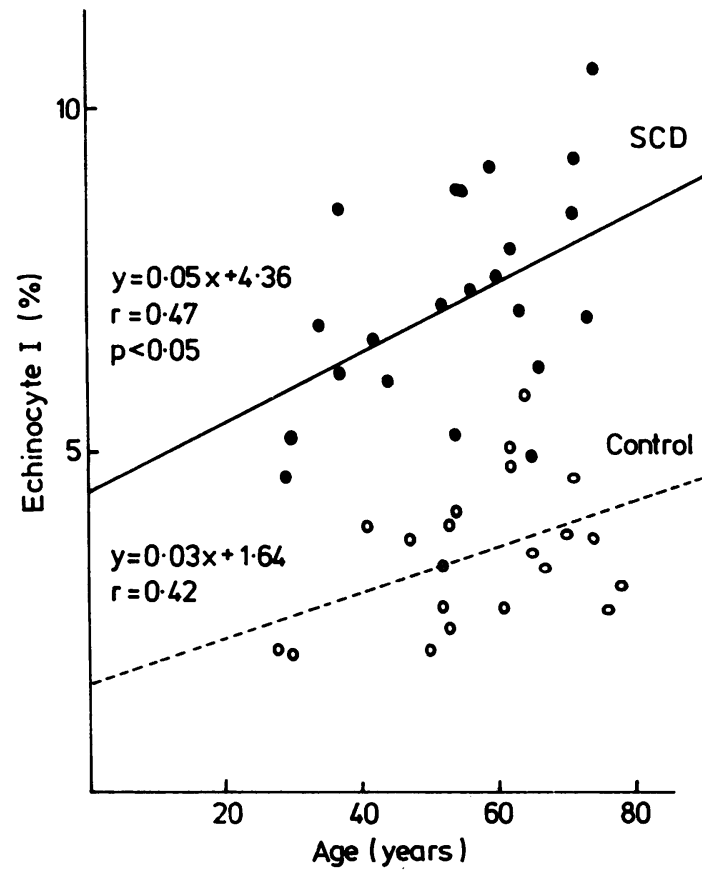

Fig 5 A correlation between age and the occurrence of Echinocyte I was found in both groups, and the echinocytic tendency in spinocerebellar degeneration was much exaggerated in the aged.

spinocerebellar degeneration compared to age and sex matched controls. A smaller increase in Echinocytes I when the $\mathrm{pH}$ was raised from $7 \cdot 2$ to 8.0 indicates that the erythrocyte membrane on spinocerebellar degeneration has less deformability, which is one of the characteristics of echinocytes. As the procedure before fixation greatly affects the shape of erythrocytes, we fixed erythrocytes immediately after drawing blood. Therefore the plasma of the patient was not found to induce echinocyte transformation of normal erythrocytes, nor was the change found to be reversible when patient's cells were suspended in normal plasma. The echinocytogenic factor may be in the erythrocyte membrane or plasma of the patients with spinocerebellar degeneration.

Hui et $a l^{29}$ reported that low density lipoprotein has an echinocytogenic effect and high density lipoprotein has an inhibitive one. It seems possible that low density lipoprotein dephosphorylates spectrin $^{30-32}$ and high density lipoprotein inhibits low density lipoprotein from attaching to the cell surface. In this study the high density lipoprotein of patients with spinocerebellar degeneration was decreased but no clear correlation between Echino- 


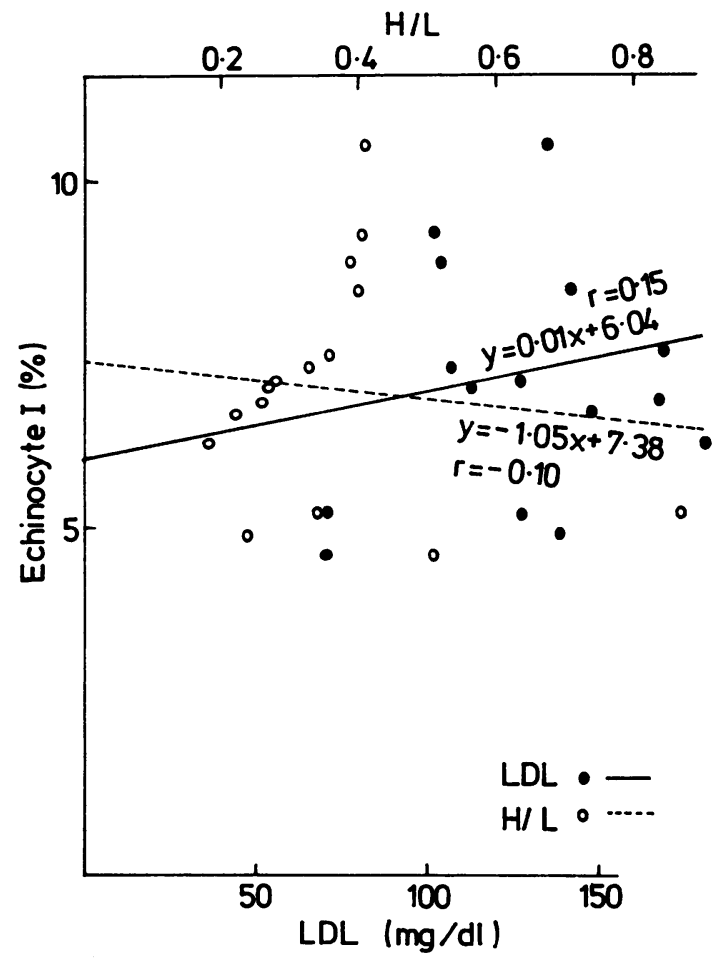

Fig 6 No correlation between the number of Echinocyte I and the concentration of serum low density lipoprotein or high density lipoprotein/low density lipoprotein ratio was found in spinocerebellar degeneration.

cyte I and low density lipoprotein or high density/ low density lipoprotein ratio was found, which may be related to the difference in the concentration of low density lipoprotein between Hui's study and ours.

It is well known that the cholesterol/phospholipid ratio in the erythrocyte membrane increases with age. ${ }^{334}$ This means that an older person has more echinocytes because the increase in the cholesterol/ phospholipid ratio in the erythrocyte membrane changes discocytes into echinocytes. ${ }^{35} 36$ We found that Echinocytes I were increased with the advance of age both in spinocerebellar degeneration and in the controls. The difference of Echinocyte I was greater in aged subjects in spinocerebellar degeneration. Thus, ageing may affect the erythrocyte morphology in spinocerebellar degeneration more, which would indicate that an investigation of the relationship between spinocerebellar degeneration and ageing is needed.

The increase of Echinocytes $I$ in spinocerebellar degeneration presents the possibility that spinocerebellar degeneration may be associated with a generalised membrane abnormality like stomatocytosis in Huntington's chorea and echinocytosis in Duchenne dystrophy. Although scanning electron microscopy study of erythrocytes may not be diagnostic for spinocerebellar degeneration and other degenerative diseases, these findings should be extended to more biochemical and biophysical investigations.

\section{References}

' Nagano Y, Roses AD. Abnormalities of erythrocyte membranes in myotonic muscular dystrophy manifested in lipid vesicles. Neurology (Minneap) 1980;30:989-91.

${ }^{2}$ Sarpel G, Lubansky HJ, Danon MJ, et al. Erythrocytes in muscular dystrophy. Investigation with ${ }^{31} \mathbf{P}$ nuclear magnetic resonance spectroscopy. Arch Neurol 1981;38:271-4.

${ }^{3}$ Markesbery WR, Butterfield DA. Scanning electron microscopy studies of erythrocytes in Huntington's disease. Biochem Biophys Res Comm 1977;78:560-4.

${ }^{4}$ Butterfield DA, Oeswein JQ, Markesbery WR. Electron spin resonance studies of membrane protein alterations in erythrocytes in Huntington's disease. Nature 1977;267:453-5.

${ }^{5}$ Butterfield DA, Roses AD, Appel SH, et al. Electron spin resonance studies of membrane proteins in erythrocytes in myotonic muscular dystrophy. Arch Biochem Biophys 1976;177:226-34.

- Butterfield DA, Chesnut DB, Roses AD, et al. Electron spin resonance studies of erythrocytes from patients with myotonic muscular dystrophy. Proc Natl Acad Sci USA 1974;71:909-13.

${ }^{7}$ Sato B, Nishida K, Samuels LT, et al. Electron spin resonance studies of erythrocytes from patients with Duchenne muscular dystrophy. J Clin Invest 1978;61:251-9.

${ }^{8}$ Wakayama Y, Hodson A, Bonilla E, et al. Freezefracture studies of erythrocyte plasma membrane in human neuro-muscular diseases. Neurology (Minneap) 1979;29:670-5.

${ }^{9}$ Landis DMD, Rosenberg RN, Landis SC, et al. Olivopontocerebellar degeneration. Arch Neurol 1974;31:295-307.

${ }^{10}$ Greenfiedl JG. The Spino-cerebellar Degenerations. Springfield: Charles C Thomas, 1954.

" Hoffman PM, Stuart WH, Earle KM, et al. Hereditary late-onset cerebellar degeneration. Neurology (Minneap) 1971;21:771-9.

12 Huang YS, Nestruck AC, Barbeau A, et al. Plasma lipids and lipoproteins in Friedreich's ataxia and familial spastic ataxia-Evidence for an abnormal composition of high density lipoproteins. Can J Neurol Sci 1978;5:149-56.

${ }^{13}$ Walker JL, Chamberlain S, Robinson N. Lipids and lipoproteins in Friedreich's ataxia.J Neurol Neurosurg Psychiatry 1980;43:111-7.

14 Matheson DW, Howland JL. Erythrocyte deformation 
in human muscular dystrophy. Science 1974; 184:165-6.

15 Matheson DW, Engel WK, Derrer EC, Erythrocyte shape in Duchenne muscular dystrophy. Neurology (Minneap) 1976;26:1182-3.

${ }^{16}$ Miale TD, Fias JL, Lawson DL. Erythrocytes in human muscular dystrophy. Science 1975;187:453.

${ }^{17}$ Miller SE, Roses AD, Appel SH. Scanning electron microscopy studies in muscular dystrophy. Arch Neurol 1976;33:172-4.

${ }^{18}$ Grassi E, Lucci B, Marchini C, et al. Deformed erythrocytes in muscular dystrophies. Neurology (Minneap) 1978;28:842-4.

${ }^{19}$ Lumb EM, Emery AEH. Erythrocyte deformation. Duchenne muscular dystrophy. $\mathrm{Br}$ Med J 1975; 23: 467-8.

${ }^{20}$ Bessis M, Weed RI, Leblond PF. Red Cell Shape. New York: Springer Verlag, 1973.

${ }^{21}$ Hattori A. Scanning electron microscopy of human peripheral blood cells. Acta Haem Jap 1972;35:45782.

22 Anderson DR, Davis JL, Carraway KL. Calciumpromoted changes of the human erythrocyte membrane. Involvement of spectrin, transglutaminase, and a membrane-bound protease. J Biol Chem 1977; 252:6617-23.

${ }^{23}$ Birchmeier W, Singer SJ. On the mechanism of ATPinduced shape changes in human erythrocyte membranes. II. The role of ATP. J Cell Biol 1977; 73:647-59.

${ }^{24}$ Cooper RA, Diloy-Pauray M, Lando P, et al. An analysis of lipoproteins, bile acids, and red cell membranes associated with target cells and spur cells in patients with liver disease. J Clin Invest 1972;51:3182-92.

${ }^{25}$ Robins SJ, Miller A. Red cell cholesterol depletion and the formation of spiculated cells in vivo. J Lab Clin Med 1974;83:436-43.
${ }^{26}$ Sheetz MP, Singer SJ. Biological membranes as bilayer couples. A molecular mechanism of drug-erythrocyte interactions. Proc Natl Acad Sci USA 1974;71: 4457-61.

${ }^{27}$ Weed RI, LaCelle PL, Medrrill EW, et al. Metabolic dependence of red cell deformability. J Clin Invest 1969;48:795-809.

${ }^{28}$ Weed RI. The importance of erythrocyte deformability. Am J Med 1970;49:147-50.

${ }^{29}$ Hui DY, Harmony JAK. Erythrocyte spectrin alteration induced by low-density lipoprotein.J Supramol Struct 1977;10:253-63.

${ }^{30}$ Lux SE. Spectrin-actin membrane skeleton of normal and abnormal red blood cells. Semin Hematol 1979;16:21-51.

${ }^{31}$ Pinder JC, Ungewickell E, Bray D, et al. The spectrinactin complex and erythrocyte shape. J Supramol Struct 1978;8:439-45.

${ }^{32} \mathrm{Yu} \mathrm{J}$, Branton D. Reconstitution of intramembrane particles in recombinations of erythrocyte protein Band 3 and lipid: Effects of spectrin-actin association. Proc Natl Acad Sci USA 1976;73:3891-5.

${ }^{33}$ Hegner D, Platt D, Heckers $\mathrm{H}$, et al. Age-dependent physiochemical and biochemical studies of human red cell membranes. Mech Ageing Dev 1979;10:117-30.

${ }^{34}$ Rivnay B, Bergman S, Shinitzky M, et al. Correlations between membrane viscosity, serum cholesterol, lymphocyte activation and aging in man. Mech Ageing Dev 1980;12:119-26.

${ }^{35}$ Arbogast LY, Rothblat GH, Leslie MH, et al. Cellular cholesterol ester accumulation induced by free cholesterol-rich lipid dispersions. Proc Natl Acd Sci USA 1976;73:3680-4.

${ }^{36}$ Cooper RA, Arner EC, Wiley JS, et al. Modification of red cell membrane structure by cholesterol-rich lipid dispersions. A model for the primary spur cell defect. $J$ Clin Invest 1975;55:115-26. 